\title{
Anaesthetic Management of Malignant Granulosa Cell Tumour of Ovary in a Paediatric Patient: A Case Report
}

\author{
Manisha Bhatt Dwivedi, Sumit Gupta, Satya Sree, Nakul Mittal, Jaggy Dhillon \\ Department of Anaesthesiology and Critical Care, MMIMSR, Mullana, Ambala, Haryana, India \\ Email: manishabhattdwivedi@gmail.com
}

Received 11 November 2015; accepted 22 December 2015; published 25 December 2015

Copyright (C) 2015 by authors and Scientific Research Publishing Inc.

This work is licensed under the Creative Commons Attribution International License (CC BY). http://creativecommons.org/licenses/by/4.0/

(c) (i) Open Access

\begin{abstract}
Juvenile granulosa cell tumour (JGCT) is very uncommon gynaecological malignancy that occurs mostly commonly in less than five years of age. Only 0.1 percent of all ovarian tumours and 4 - 5 percent of granulosa cell tumours present as JGCT. The most common presentation of these tumours in children is precocious puberty. We describe anaesthetic management of a case of JGCT in a 1-year-old girl. The malignancy is assigned to International Federation of Gynaecology and Obstetrics staging system (FIGO stage I). It was treated with complete excision and histological examination confirmed the diagnosis.
\end{abstract}

\section{Keywords}

Juvenile Granulosa Cell Tumour, Anaesthetic Management, Haemodynamic Alteration, Respiratory Distress

\section{Introduction}

Ovarian juvenile granulosa cell tumour (JGCT) is extremely rare sex cord-stromal tumour [1]. Typically, they present as sexual precocity in prepubertal girls due to excessive oestrogen production. In some rare cases, androgens may be produced [2]. JGCT is different from adult granulosa cell tumour (AGCT) which is seen in older females with respect to clinical and pathological features as well as biological behaviours [3]. Common symptoms include abdominal swelling, abnormal uterine bleeding, appearance of acne, breast enlargement and occasional facial hair appearance. There are no known risk factors for this tumour but recently, associations with changes in certain chromosomes are suspected [4]. The more serious oestrogen effects can occur in various end organs such as endometrial hyperplasia, endometrial adenocarcinomas and increased the risk of breast cancer [5]. 
These serious complications along with excellent prognosis of JGCT after salpingo-oophorectomy [6] emphasize the need for early surgical intervention.

Anaesthetic management for such surgeries is very challenging.

During anaesthesia, difficulty in intubation, and complications associated with cardiovascular and respiratory systems which can threaten life, may develop. Large ovarian masses exert pressure on large vessels and adjacent organs. After the giant tumour is removed, rapid fall in thoracic pressure and expansion thereafter can cause lung oedema. Aspiration of fluid during excision of giant mass may give rise to severe hypotension or inferior vena cava syndrome [7] [8].

The aim of the present case was to draw attention towards the hemodynamic alterations and respiratory distress which might develop in patients during surgical excision of giant ovarian masses.

\section{Case Report}

One year old female weighing $8.5 \mathrm{~kg}$ presented to paediatric surgery outpatient clinic with history of weight loss, abdominal swelling and pain in abdomen since 2 months. Examination revealed bilateral breast enlargement (Figure 1) and premature appearance of pubic hair (Tanner stage 1) (Figure 2) without significant peripheral lymphadenopathy. A lump in abdomen measuring approximately $8 \times 10 \mathrm{~cm}$ in size extending from epigastrium till pelvis was present. Abdominal CECT findings (Figure 3) confirmed a heterogeneously enhancing well defined abdominopelvic mass extending from right adnexa up to the subhepatic region superiorly, suggestive of ovarian origin.

The patient was taken to operation theatre and peripheral venous cannulation was carried out with $22 \mathrm{G}$ catheter. Monitors were applied for electrocardiogram (ECG), oxygen saturation $\left(\mathrm{SpO}_{2}\right)$, end tidal capnography and non-invasive blood pressure monitoring. In order to prevent hypotension which may develop following mass excision, $10 \mathrm{ml} / \mathrm{kg}$ fluid resuscitation was performed with Ringer lactate. Following adequate preoxygenation,

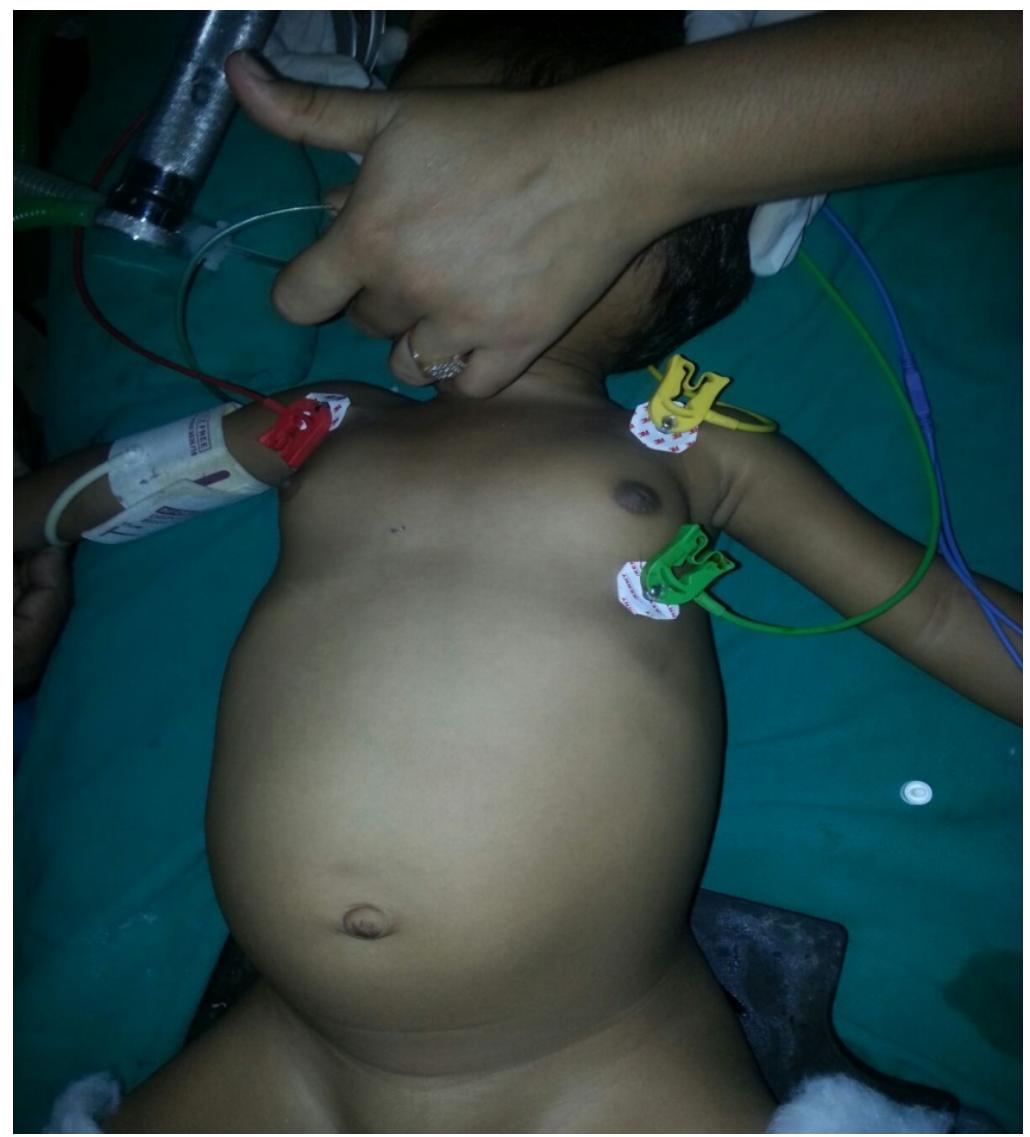

Figure 1. Showing bilateral breast enlargement and distended abdomen. 


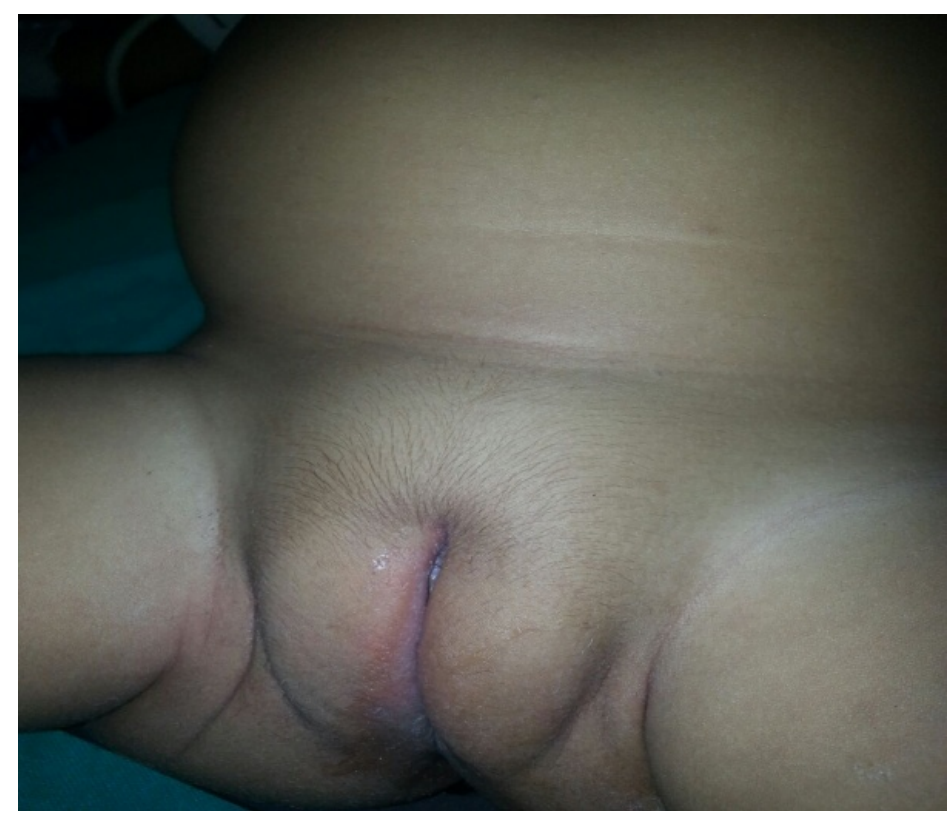

Figure 2. Pubic hair appearance.

induction of anaesthesia was done with $1 \mathrm{mcg} / \mathrm{kg}$ fentanyl, $2 \mathrm{mg} / \mathrm{kg}$ propofol, and rocuronium $0.6 \mathrm{mg} / \mathrm{kg}$ was administered. Patient was intubated with cuffed endotracheal tube $(3.5 \mathrm{~mm})$ and was ventilated at low pressure to avoid excessive pressure on large vessels by the giant mass. Adequate analgesic cover was provided with paracetamol suppository per rectum inserted immediately after induction and I/V fentanyl $0.5 \mu \mathrm{g} / \mathrm{kg}$ intraoperatively. Local infiltration of the surgical incision was done with $7 \mathrm{ml}$ of $0.125 \%$ bupivacaine. Urine output and blood loss was monitored. A mass of $2900 \mathrm{~g}$ was removed during operation (Figure 4). Patient was haemodynamically stable during operation and extubation was uneventful. The specimen was sent for histopathological examination which confirmed the diagnosis (Figure 5).

\section{Discussion}

Respiratory and circulatory management is especially difficult in giant ovarian masses. Large mass leads to pathology by exerting pressure on large vessels and adjacent organs. It has got the risks of difficult intubation and aspiration due to mass pressure. Also, the risk of massive bleeding is present. With the expansion of lungs following excision of the mass, pulmonary oedema may develop. Due to these risks, preoperative preparation is necessary in order to prevent the negative impact of tumour mass on circulatory and respiratory system [9] [10]. Large abdominal tumours may lead to impairment of respiratory functions by raising the diaphragm and narrowing the chest cavity. Following the administration of muscle relaxant, compliance between lung and diaphragm is impaired, making respiratory management even more difficult. High airway pressure may also lead to lung injury [11]. Excision of giant masses may lead to bleeding and hypotension, electrolyte disturbances as well as morbidity and other serious problems. Pressure on vessels and positive pressure ventilation may cause venous return to decrease. In association with the suppression of sympathetic activity by general anaesthesia, symptomatic inferior vena cava syndrome and hypoxemia may develop [12].

Supine hypotensive syndrome has been reported in pregnant women and in those with giant abdominal masses related to changing pressure in inferior vena cava. Peripheral oedema, dyspnea, orthopnea, decreased and increased jugular pressure are the findings which may present in patients with large abdominal mass. This syndrome is sometimes compensated by a balance produced between blood pressure, cardiac output, and peripheral vasoconstriction via sympathetic system. Sympathetic blockade impairs these compensatory mechanisms and therefore symptoms of decreased venous return becomes more marked [13] [14] presenting as severe hypotension in patients in which central neuraxial block is given .Spinal and epidural anaesthesia should be avoided in such cases for the same reason. However, few cases have been reported in which epidural anaesthesia has been employed for cyst decompression without causing circulatory depression and pulmonary oedema. 




Figure 3. CECT whole abdomen. 




Figure 4. Ovarian tumour after excision.



Figure 5. Histopathology picture.

With the above discussion it is clear that for better anaesthetic management and postoperative intensive care, each case should be carefully evaluated by anaesthesiologist in preoperative period and blood products should be arranged due to probability of bleeding and coagulation disorder. ECG, $\mathrm{SpO}_{2}$, BP, urine output, and bleeding should be continuously monitored. If necessary, central catheterization, arterial cannulation, and blood gas 
monitoring should be carried out. In postoperative period, frequent haemograms grams and electrolyte evaluations are recommended.

\section{Conclusion}

Giant ovarian mass excision may lead to life threatening problems due to serious respiratory and cardiovascular disorders. Haemodynamic monitoring, respiratory monitoring and fluid management are the keys to successful outcome. The most important prognostic criterion for the mass localized to ovary is complete surgical resection and the patients respond well to surgery alone.

\section{References}

[1] Wang, Y., Wang, W., Xu, C., Huang, X., Zhong, L., Kang, X., et al. (2011) Childhood Ovarian Juvenile Granulose Cell Tumour: A Retrospective Study with Three Cases Including Clinical Features, Pathologic Results and Therapeutics. Journal of Pediatric Hematology/Oncology, 3, 1-5.

[2] PathologyOutline.com (2011) Juvenile Granulose Cell Tumour. 1-4. http://www.pathologyoutline.com/

[3] Igberase, G.O. and Ebeigbe, P.N. (2006) Huge Benign Granulose Cell Tumour in a 61-Year Old Nigerian Grandmultipara with Late Presentation. Benin Journal of Postgraduate Medicine, 8, 61-66.

[4] Nicolas, K., Ande, E., Catherine, P., Pierre, D., Francoise, A., Catherine, P., et al. (2006) Activating Mutations of the Stimulatory G Protein in Juvenile Ovarian Granulose Cell Tumour: A New Prognostic Factor. The Journal of Clinical Endocrinology \& Metabolism, 91, 1842-1847. http://dx.doi.org/10.1210/jc.2005-2710

[5] Chad, M.M. (2011) Granulosa-Theca Cell Tumours. http://www.emedicine.medscape.com/article/254487-overview

[6] Merras-Salmio, L., Vettenranta, K., Mottonen, M. and Heikinheimo, M. (2002) Ovarian Granulose Cell Tumours in Childhood. Pediatric Hematology and Oncology, 19, 145-56. http://dx.doi.org/10.1080/088800102753541297

[7] Tagge, D.U. and Baron, P.L. (1997) Giant Adrenal Cyst: Management and Review of the Literature. The American Surgeon, 63, 744-746.

[8] Soslow, R.A. (2008) Histological Subtypes of Ovarian Carcinoma: An Overview. International Journal of Gynecological Pathology, 27, 161-174.

[9] Nishiyama, T. and Hanaoka, K. (1997) Same Day Drainage and Removal of a Giant Ovarian Cyst. Canadian Journal of Anaesthesia, 44, 1087-1090. http://dx.doi.org/10.1007/BF03019231

[10] Kotera, A., Kouzuma, S., Miyazaki, N., Taki, K. and Esaki, K. (2009) Anesthetic Management of a Patient with an Ultra Huge Ovarian Tumor. Masui, 58, 907-909.

[11] Shinohara, H., Ishii, H., Kakuama, M. and Fukuda, K. (2010) Morbidly Obese Patient with a Huge Ovarian Tumour Who Was Intubated While Awake Using Airway Scope in Lateral Decubitus Position. Masui, 59, 625-628.

[12] Aydin, A.A., Özdemir, S., Pakay, K., Sivrikaya, U., Polat, N., et al. (2013) Giant Ovarian Masses, Gynaecologic, Anaesthetic and Pathologic Assessment; Analysis of Four Cases. SETB, 47, 35-40.

[13] Haspels, A.A. and Zuidema, P.J. (284) A Giant Ovarian Cyst in a Javanese Woman. British Medical Journal, 284, 1410. http://dx.doi.org/10.1136/bmj.284.6326.1410-b

[14] Morrison, P. and Morgan, G. (1987) Removal of a Giant Ovarian Cyst. Anaesthetic and Intensive Care Management. Anaesthesia, 42, 965-974. http://dx.doi.org/10.1111/j.1365-2044.1987.tb05368.x 